\title{
A CROSS-CULTURAL COMPARISON OF THE STRESS EXPERIENCED BY HIGH-LEVEL CAREER WOMEN
}

\author{
HENRIETTE S VAN DEN BERG \\ Department of Psychology \\ University of the Free State \\ South Africa \\ EBBEN S VAN ZYL \\ Department of Industrial Psychology \\ University of the Free State \\ South Africa \\ Correspondence to: Henriette S van den Berg \\ e-mail: vdberghs.hum@ufs.ac.za
}

\begin{abstract}
This study examines differences in the experience of work-related stress and of exposure to workrelated stressors among South African career women of different ethnic groups. A sample of 732 women working in administrative, semi-professional, professional and managerial positions was involved. Analyses of covariance found significant differences in the level of stress reported by the different groups, with black women reporting the highest level of stress. Stressors pertaining to a lack of infrastructure and resources in the environment significantly contributed to the stress experienced by black women. All four groups reported discontent with their remuneration and fringe benefits.
\end{abstract}

Keywords: South African career women, occupational stress, job-related stressors, conservation-ofresources theory, criterion group design

The composition of the South African labour force is rapidly changing. During the past three decades, the participation of women in the formal labour market, for example, has increased significantly. Msimang (2001), in fact, emphasises the increasing numbers of women, specifically black women, who are moving into high-level careers due to the impact of the Employment Equity Act. Unfortunately, these women are not exempt from the stressful consequences of their increased involvement in the formal labour market. Erasmus (1998) found in a study of the stress experiences of high-level career women from different ethnic groups that more than half reported problems with high levels of work-related stress. Some researchers (Erwee, 1994; Møller, 1998) even suggest that the impact of the Employment Equity Act, which encourages the promotion of more women to managerial positions, may lead to increased levels of stress among women because of their lack of training and the negative impact of gender discrimination on the adjustment of women. What seems to play an important role in the difficulties experienced by many career women is the lack of investment in resources like training, decision-making authority and social support.

The conservation-of-resources model of stress (Hobfoll, 1989; 1998) was used as the guiding model to conceptualise this study. Hobfoll (1989) strongly supports an ecological approach to stress that emphasises the importance of thinking of people as members of social systems and structures. According to Hobfoll's model, stress develops due to an imbalance between the perceived threat and the perceived ability to master the threat. This model seems to fit in well with a cross-cultural perspective of stress because of its strong focus on the objective reality of stressful situations. Hobfoll (1988, p.25) defines stress as

"a reaction to the environment, in which there is either a) the threat of a net loss of resources, b) the net loss of resources, or c) the lack of resource gain following the investment of resources".

Resources serve as a means of helping individuals to realise their goals and to gain control over their environment. They are described as any object, personal trait, condition or energy that is of value to an individual and that can be used to gain access to more resources. Socio-cultural circumstances play an important role in the distribution of resources and in the creation of the life context that determines the individual's perception of threats and of the capacities to master these threats.

According to this ecological model, the consideration of ethnic differences in the experience of stress is essential because researchers have to determine whether perceived differences in the level of stress experienced by people from different ethnic groups are not simply the result of the impact of differences in social status and educational level (Hobfoll, 1998). Thus, from an ecological perspective, it is important to study the differences in the exposure to different stressors because stressors are described as inadequate resources to overcome threats and challenges.

Researchers like Landrine and Klonoff (1997) state that women are exposed to a greater variety of and more frequent stressors than their male counterparts, due to the negative impact of gender discrimination, lack of opportunities for advancement and family-work interface problems. The stressors that women are exposed to are also closely intertwined with community traditions and values regarding gender equity, women's responsibility for domestic and family responsibilities, the distribution of power between men and women as well as the socio-economic climate that influences the availability of resources and the financial security of all workers. Gender discrimination often restricts the opportunities for the training and development of women. Many researchers emphasise the uneven distribution of power, financial resources, status and opportunities that place women (especially black women) in a disadvantaged position with fewer resources than their male colleagues (Møller, 1998; Sibiya, 1993).

The current financial pressure on families caused by increasing unemployment rates, affirmative action and the ever-increasing gap between the rich and poor are placing undue stress on the whole family system, where women are taking on more 
TABLE 1

Significance of the differences in the various racial groups on the scales and subscales

\begin{tabular}{lrc}
\hline VARIABLE & f VALUE DEGREES OF & LEVEL OF SIGNIFICANCE P \\
\hline WLE scale (stress level) & \multicolumn{2}{c}{ F VALUE PRACTICAL } \\
SIGNIFICANCE
\end{tabular}

$\mathrm{N}=732 * * \mathrm{p} \leq 0.01$ Level of significance ${ }^{* *} \mathrm{p} \leq 0.1$ Level of significance $* \mathrm{p} \leq 0.5$ Level of significance

$\bullet \bullet \mathrm{f}=0.4$ large effect $\bullet \bullet \mathrm{f}=0.25$ medium effect $\bullet \mathrm{f}=0.1$ small effect

responsibility for the financial survival of their families (Els \& Van Vuuren, 1998). These role reversals are leading to additional stress because of the added pressure on women to make progress in their careers and to provide a stable home environment. The lack of infrastructure and of basic services, as well as poor living conditions are further sources of frustration for women living in townships. A lack of resources like adequate salaries and benefits, stable home environments, training and development opportunities as well as supportive work environments is contributing to the high levels of stress reported by women from previously disadvantaged groups (Bennett, 2003; Møller, 1998; Msimang, 2001)

Within the work environment, the disproportionate relationship between excessive demands and inadequate resources also adds to the stress experienced by working women. Gender and racial discrimination leads to social isolation and a lack of control over demands because of a lack of power and it influences access to resources necessary to cope with the frequent exposure to the demands that women have to overcome. With regard to organisational functioning, many women experience difficulty in communicating effectively with their dominantly male supervisors. Performance criteria are often vague, goalposts are shifted and many women complain that their opinions seem to carry less weight than those of their male colleagues (Cartwright \& Cooper, 1997; Rosener, 1995). On the one hand, the task characteristics of female workers sometimes reflect negative gender stereotyping of female workers as less important and less capable of high-level tasks (Bennett, 2003). On the other hand, workers with inadequate training and skills who are promoted to high-level positions because of the pressure of employment equity legislation experience stress because of qualitative overload (Erwee, 1994). The large numbers of female workers in helping professions like nursing and social work also experience qualitative overload because of the emotionally demanding nature of their work (Blosser, 2000). More women furthermore report frequent exposure to quantitative overload and too-long work hours. The physical work environment of many women poses an additional stressor, especially for workers in the public sector like schools, hospitals and government institutions, where the physical environment and work equipment are neglected because of budget constraints that result from increased spending on social services (Van der Walt, 2000). Although changes in government spending have provided for some of the needs of black workers such as houses, schools and medical services, the lack of equipment, building maintenance and basic services in some institutions creates unnecessary frustration when it interferes with the execution of essential tasks.

With regard to the career path of women, women of all ethnic groups experience frustration because of their slow progress, a lack of training opportunities and a lack of career planning for women in companies (Rosener, 1995). Pretty, McCarthy and Catano (1992) also found that women tend to be more sensitive to the quality of work relationships and that problems with co-workers impact more negatively on female workers. Exclusion from male-dominated networks, a lack of social support and difficulty in finding same-sex mentors all contribute to additional strain in female workers. Black women may experience more isolation because of differences between their culture and the dominantly white, Westernised culture in organisations. Lastly, the negative influence of gender discrimination on the remuneration and fringe benefits of female workers is stated by researchers internationally. Jacobs (1999) found in a study done by the Human Sciences Research Council among graduated workers that men with the same qualifications and number of years' experience still earn more than their female colleagues. The lower salaries and poor fringe benefits are important barriers to the financial independence of working women and prevent women from acquiring the resources necessary to overcome the obstacles that they face in their career environment. The fact that more and more women are the sole providers for their families unfortunately also limits the chances of financial security for their families (Sibiya, 1993).

As can be concluded from the literature overview, women from different ethnic groups are exposed in different ways to a variety of stressors. It may therefore be expected that the levels of stress that they experience also differ significantly.

The objective of this study was to examine the influence of ethnic differences in the experience of work-related stress and to investigate the differences in perceived exposure to a number of stressors within and outside the work environment.

The research question of this study was whether black, white, coloured and Asian career women differ significantly regarding their levels of stress and regarding the nature and extent of their exposure to work and non-work-related stressors.

The following research hypotheses were formulated:

Null hypothesis 1: Career women from different ethnic groups do not differ significantly with regard to the level of stress that they experience.

Alternative hypothesis 1: Career women from different ethnic groups differ significantly with regard to the level of stress that they experience.

Null hypothesis 2: Career women from different ethnic groups do not differ significantly with regard to the nature and frequency of stressors that they are exposed to.

Alternative hypothesis 2: Career women from different ethnic groups differ significantly with regard to the nature and frequency of stressors that they are exposed to. 


\section{RESEARCH DESIGN}

\section{Research approach}

This article is based on a cross-sectional survey. A criteriongroup design was used as research approach in the study that this article is based upon. Participants from four race groups were compared with regard to their reported levels of stress and to their job-related and non-job-related stressors.

\section{Research method}

\section{Participants}

A convenience sample of 732 career women was used in this study. The women were recruited through the human resources departments of financial institutions, of publicsector institutions like schools, hospitals and provincial government offices and of medium-sized businesses, and business associations for career women as well as church groups. The distribution according to race was $38.5 \%$ black (282), 32.7\% white (239), $15 \%$ coloured (110) and $13.8 \%$ Asian (101). The youngest participant was 21 years old and the oldest 57 years, with an equal distribution of participants in the age categories 21 to 29 years, 30 to 39 years and 40 years and older. All the participants had a minimum of a Grade 12 qualification, with $75 \%$ of the group having tertiary education; $50 \%$ of the group had more than three years of tertiary education. Three career categories were distinguished, namely administrative or clerical ( $42 \%$ ), social services (nursing, teaching, social work) $(40 \%)$ and professional or managerial (18\%). Furthermore, 354 $(48.4 \%)$ of the participants were married, $267(36.5 \%)$ were single and $111(16.1 \%)$ were divorced, and $68 \%$ of the participants had children

\section{Measuring instruments}

A self-compiled biographical questionnaire was used in this study. It consisted of six questions about the participants' ethnic group, age, educational qualifications, job description, marital status and number of children.

The Work and Life Experiences Questionnaire (WLE) (Van Zyl, 1994) was used to measure the level of stress and the causes of stress experienced by the participants. This questionnaire was standardised for use with high-level South African workers from different ethnic groups. It consisted of 116 items, with 40 items that measured the level of stress, 16 items that measured non-work-related causes of stress and 60 items that measured 6 different types of work-related stressors (organisational functioning, task characteristics, physical work environment, career matters, social matters, and remuneration and fringe benefits). A principal-axis factor analysis (the Varimax method) was run on the 16 items of the non-work-related causes. Three factors emerged from this: psychosocial problems (including conflict in relationships, bereavement, a lack of social status), infrastructure (a lack of basic services, poor housing) and socioeconomic problems (financial problems).

\section{Research procedure}

The researcher and 15 fieldworkers who assisted with the data-gathering process approached 1000 career women and requested them to participate in the study. The participants had been recruited during visits to private and public-sector organisations, to associations for career women and to church groups. Instructions for the completion of the questionnaires were explained to the participants and arrangements were made for the return of the questionnaires to the fieldworkers within a period of one week. The voluntary nature of participation and the confidentiality of responses were also explained to the participants. Those participants interested in feedback about their results were requested to identify themselves on the questionnaires to enable the research team to provide them with written feedback. The data were gathered over a period of three months and a total of 768 questionnaires were returned. Due to incomplete responses on 36 of the questionnaires returned, only 732 were coded and captured electronically.

\section{Statistical analysis}

The statistical significance of the differences among the ethnic groups was determined with the aid of the analysis of covariance (ANCOVA) and the practical significance was established through the determination of Cohen's effect sizes (Steyn, 1999).

\section{RESULTS}

As can be concluded from Table 1, the groups differed significantly on most of the variables. The differences among the racial groups in organisational functioning, career matters and social matters were not, however, significant. The differences among the four groups were of small practical significance regarding the following variables: stress levels, causes outside work (social), causes outside work (economic), task characteristics, and remuneration and fringe benefits. The differences found in the physical work environment were of medium significance.

TABLE 2

Specific racial differences with regard to stressors related to and not related to work

\begin{tabular}{|c|c|c|c|c|c|c|c|c|c|}
\hline \multirow[t]{2}{*}{ VARIABLE } & \multicolumn{2}{|c|}{$\begin{array}{c}\text { WHITE GROUP } \\
N=239\end{array}$} & \multicolumn{2}{|c|}{$\begin{array}{c}\text { BLACK GROUP } \\
N=282\end{array}$} & \multicolumn{2}{|c|}{$\begin{array}{c}\text { COLOURED GROUP } \\
N=110\end{array}$} & \multicolumn{2}{|c|}{$\begin{array}{c}\text { ASIAN GROUP } \\
N=101\end{array}$} & \multirow{2}{*}{$\begin{array}{l}\text { GROUPS THAT DIFFER } \\
\text { SIGNIFICANTLY FROM ONE } \\
\text { ANOTHER ACCORDING TO } \\
\text { THE SCHEFFÉ TEST }\end{array}$} \\
\hline & Mean & $\begin{array}{l}\text { Standard } \\
\text { deviation }\end{array}$ & Mean & $\begin{array}{l}\text { Standard } \\
\text { deviation }\end{array}$ & Mean & $\begin{array}{l}\text { Standard } \\
\text { deviation }\end{array}$ & Mean & $\begin{array}{l}\text { Standard } \\
\text { deviation }\end{array}$ & \\
\hline Work-related stress & 74.70 & 23.10 & 82.25 & 21.45 & 79.59 & 21.64 & 74.75 & 22.25 & Black from white and Asian \\
\hline $\begin{array}{l}\text { Non-work-related stressors } \\
\text { Total score }\end{array}$ & 27.56 & 7.09 & 36.69 & 9.05 & 34.10 & 10.72 & 31.49 & 7.32 & Black from white and Asian \\
\hline $\begin{array}{l}\text { Non-work-related stressors } \\
\text { Psycho-social }\end{array}$ & 11.35 & 3.33 & 13.65 & 4.61 & 13.23 & 4.94 & 12.59 & 3.40 & White from black and coloured \\
\hline $\begin{array}{l}\text { Non-work-related stressors } \\
\text { Socio-economic }\end{array}$ & 9.12 & 3.23 & 10.92 & 3.45 & 9.712 & 3.48 & 9.96 & 3.12 & Black from white and coloured \\
\hline $\begin{array}{l}\text { Non-work-related stressors } \\
\text { Infrastructure }\end{array}$ & 7.28 & 2.71 & 12.11 & 3.76 & 11.13 & 4.40 & 8.96 & 3.02 & $\begin{array}{l}\text { Asian from black, } \\
\text { white and coloured, } \\
\text { white and black, } \\
\text { coloured and Asian }\end{array}$ \\
\hline \multicolumn{10}{|l|}{ Work-related causes } \\
\hline Task characteristics & 47.07 & 10.14 & 43.35 & 10.01 & 42.11 & 10.08 & 45.47 & 9.17 & White from black and coloured \\
\hline Physical work environment & 23.87 & 7.22 & 17.24 & 7.44 & 19.09 & 7.28 & 20.89 & 7.19 & $\begin{array}{l}\text { White from black, coloured and } \\
\text { Asian; } \\
\text { Asian from black and coloured; } \\
\text { coloured from black }\end{array}$ \\
\hline $\begin{array}{l}\text { Remuneration and fringe } \\
\text { benefits }\end{array}$ & 23.18 & 10.02 & 19.41 & 8.61 & 20.43 & 9.48 & 21.13 & 10.18 & White from black \\
\hline
\end{tabular}


The effect size of the differences that emerged in the causes outside work (the total score) and causes outside work (infrastructure) was large, indicating a high practical significance. See Table 2 for the specific differences regarding the stressors related to and not related to work.

\section{DISCUSSION}

The women from the four racial groups differed significantly in the levels of work stress that they experienced. The black women reported the highest stress levels, these being significantly higher than the stress levels reported by the white and Asian women. These findings are consistent with the findings of Jackson and Sears (1992) and Møller (1998), who posit that differences in access to resources like good training, high-level posts and sufficient remuneration hamper black women's ability to master work-related demands and that these therefore result in higher stress levels in black women. It seems that black women are exposed to significantly (a high practical significance) more non-work-related stressors than white and Asian women, the mean scores of the black participants reflecting a high stress level. Large differences exist among the four racial groups regarding the three subcomponents of thenonwork-related stressors subscale, namely psychosocial stressors, poor infrastructure and socio-economic problems. This finding supports findings by Sibiya (1993), Møller (1998) and Msimang (2001) in that differences in access to transport, housing, basic services and recreational facilities play an important role in the stress experience of black women. The white women reported the least problems with infrastructure, the Asian women reported more than the white women but less than the coloured and black women. The black women also experienced the most problems with economic crises and psychosocial problems, while the coloured women experienced significantly more psychosocial problems than the white women. This may be associated with the marginalisation of black and coloured women who work in organisations in a predominantly white, Westernised organisational culture. It may also mean that the black women experienced more economic and family problems due to their insufficient contextual resources, which leave them vulnerable and restrict their ability to cope effectively with environmental demands.

With regard to stressors within the work environment, significant differences were found among the groups on task characteristics, physical work environment and remuneration and fringe benefits. The black and coloured women reported significantly more stress regarding their work characteristics. This may be due to either overload or under-load (an itemspecific analysis is necessary to determine the exact cause). It may also be due to poor communication regarding performance expectations, which leads to uncertainty and misunderstanding. The black, coloured and Asian women reported significantly higher levels of dissatisfaction with their physical work environment. The mean score of the Asian participants was significantly lower than that of the white participants but it was still higher than the mean scores of the black and coloured participants. With regard to the mean score on the remuneration and fringe-benefit subscale, the white women's score was significantly higher than that of the black participants. It is important to note that the mean scores of all four groups were significantly lower than those reported by Van Zyl (1991). This is indicative of the dissatisfaction of these women with their remuneration and benefits.

\section{CONCLUSION}

Government institutions and private companies must realise the necessity of support for gender-equity policies. Investment in the provision of better infrastructure in disadvantaged communities, of sufficient training and of equal remuneration and benefits for all workers are also important for the successful adjustment of career women. Without the real support of monetary investment to help improve access to resources, measures to redress the inequities of the past will fail and will perpetuate a self-fulfilling prophecy where the abilities of female workers are questioned, yet, because of legislation aimed at redressing gender and racial practices, where women (especially from designated groups) are appointed in larger numbers but without the resources that help them to deal effectively with the high demands of their jobs and multiple roles. When they then succumb to the stress of the high demands and the lack of resources to master these demands, the beliefs about the inability of women to succeed in demanding careers are maintained.

It is suggested that future research should focus on more homogenous groups of career women. A longitudinal followup of women to report on their career progress as well as on the development of skills to overcome the obstacles that they encounter can also be of great value to researchers and human research practitioners. With regard to human resource management practices, more support for female workers, especially with regard to training, stress management skills and mentoring programmes can make a valuable contribution to the well-being of high-level career women.

\section{REFERENCES}

Bennett, J. (2003). Women: The struggle continues. Sunday Times. Retrieved February 29, 2004, from the World Wide Web: http://www.suntimes.co.za/2003/08/03/business/ news/news12.asp.

Blosser, F. (2000). Working women face high risks from work stress, musculoskeletal injuries, other disorders, NIOSH finds. National Institute for Occupational Safety and Health. Retrieved February 27, 2004, from the Workd Wide Web: http://www.cdc.gov/niosh/womrisk.html.

Cartwright, S. \& Cooper, C.L. (1997). Managing workplace stress. London: Sage.

Cooper, C.L. \& Sutherland, V.J. (1992). The stress of the executive lifestyle: Trends in the 1990s? Management Decision, 30(6), 64-68.

Els, C. \& Van Vuuren, M.V.J. (1998). Stress in the family system. Continuing Medical Education, 16(1), 27-32.

Erasmus, B. (1998). Women power: Aspects of working life in the late 1990s. Management Today, pp. 25-29.

Erwee, R. (1994). South African women: Changing career patterns. In N.J. Adler \& D.N. Izraeli (Eds), Competitive frontiers: Women managers in a global economy. Cambridge, Massachusetts: Blackwell Business, pp. 325-343

Hobfoll, S.E. (1988). The ecology of stress. New York: Hemisphere.

Hobfoll, S.E. (1989). Conservation of resources: A new attempt at conceptualizing stress. American Psychologist, 44(3), 513524.

Hobfoll, S.E. (1998). Stress, culture and community. New York: Plenum Press.

Jackson, A.P. \& Sears, S.J. (1992). Implications of an Africentric worldview in reducing stress for African American women. Journal of Counselling and Development, 71, 184-191.

Jacobs, J. (1999). Remuneration trends. The Graduate. HSRC Newsletter, Pretoria, pp. 12-17.

Landrine, H. \& Klonoff, E.A. (1997). Discrimination against women: Prevalence, consequences, remedies. London: Sage.

Long, B.C. (1998). Coping with workplace stress: A multiple group comparison of female managers and clerical workers. Journal of Counselling Psychology, 45(1), 65-78.

Maturi, R. (1992). Stress can be beaten. Industry Week, pp. 22-26.

Mkhwanazi, D. (1993). New breed of managers needed for a new South Africa. Human Resources Management, pp. 14-17.

Møller, V. (1998). Quality of life in South Africa: Post-apartheid trends. Social Indicators Research, 43, 27-68. 
Msimang, S. (2001). Affirmative action in the new South Africa: The politics of representation, law and equity. Women in Action. Retrieved on March 1, 2004, from the World Wide Web: http://www.isiswomen.org/pub/wia/wiawcar/ affirmative.htm

Pretty, G.M.H., Mccarthy, M.E. \& Catano, V.M. (1992). Psychological environments and burnout: Gender considerations within the corporation. Journal of Organizational Behaviour, 13, 701-711.

Rosener, J.B. (1995). America's competitive secret: Women managers. Oxford: Oxford University Press.

Schlebusch, L. (1998). Recent advances in stress research and implications for health and well-being. In L. Schlebush, South Africa beyond transition: Psychological well-being. Pretoria: Psyssa, pp. 265-283
Sibiya, E. (1993). From banishment to boardroom. SAJHE/ SATHO, 7(3), 15-25.

Steyn, H.S. (1999). Praktiese beduidendheid: Die gebruik van effekgroottes. Potchefstroom: Publication Control Committee, Potchefstroom University.

Taylor, S.E. (1995). Health psychology. New York: McGraw-Hill. Van der Walt, L. (2000). Gear versus social welfare. South African Labour Bulletin, 24(3), 70-75.

Van Zyl, E.S. (1991). Die ontwikkeling van 'n meetinstrument van werkstres vir hoëvlak-werknemers. DComm dissertation, Pretoria: Pretoria University.

Van Zyl, E.S., Van der Walt, H.S. \& Brand, H.E. (1994). Die ontwikkeling van 'n meetinstrument van werkstres. Tydskrif vir Bedryfsielkunde/South African Journal of Industrial Psychology, 20(4), 22-28. 